Adriel Dalmolin Zortéa' Daniela Queiroz Campos ${ }^{2}$

\title{
A ninfa nos azulejos de Adriana Varejão
}

The nymph in the tiles of Adriana Varejão

La nymph dans les tuiles de Adriana Varejão 


\title{
Resumo
}

O estudo aponta a ninfa na obra da artista plástica Adriana Varejão (1964-). Nascida no Rio de Janeiro, as imagens da brasileira Adriana Varejão destacam-se no circuito artístico contemporâneo. Analisam-se as imagens a partir de questões teóricas articuladas com a Ninfa, formuladas pelo historiador da arte Aby Warburg em sua fértil obra, incorporadas e revisitadas pela história da arte escrita por Georges Didi-Huberman. As ninfas em Varejão foram indicadas em três de suas imagens da série Saunas e Banhos - entranhadas ao azulejo, tema/objeto caro à artista - a partir de similitudes para com imagens produzidas em outros tempos históricos, também problematizadas como ninfas.

Palavras-chave: Adriana Varejão. Ninfa. Azulejo. Arte contemporânea.

\begin{abstract}
This article focuses on the Nymph present in the works of plastic artist Adriana Varejão (1964-). Born in Rio de Janeiro, Varejão's imagery is a highlight in the contemporary artistic circuit. The images are analyzed through theorical questions articulated with the Nymph, raised by art historian Aby Warburg works, and incorporated and revisited by the works of Georges Didi-Huberman in art history. The nymphs in Varejão were singled out from three of the images present in the series Saunas e Banhos - entangled in the tiles, beloved object by the artist - through the similarities with images produced in other historical periods, also problematized as nymphs.
\end{abstract}

Key-words: Adriana Varejão. Nymph. Tile. Contemporany Art.

\section{Résumé:}

L'étude met en évidence une nymphe dans l'œuvre de l'artiste Adriana Varejão (1964-). Née à Rio de Janeiro, les images de la brésilienne Adriana Varejão se démarquent dans le circuit artistique contemporain. Les images sont analysées à partir de questions théoriques articulées avec la Nymph, formulées par l'historien de l'art Aby Warburg dans son œuvre fertile, incorporées et revisitées par l'histoire de l'art écrite par Georges Didi-Huberman. Les Nymphes en Varejão ont été indiquées dans trois de leurs images de la série Saunas e Banhos - enracinées avec la tuile, objet chère à l'artiste - basées sur des similitudes avec des images produites à d'autres époques historiques, également problématisées comme Nymphes.

Mots clés: Adriana Varejão. Nymphe. Tuile. Art contemporaine.

\footnotetext{
Graduando em História pela Universidade Federal de Santa Catarina (UFSC). Foi bolsista do Programa de Educação Tutorial (PET). É bolsista de Iniciação Científica do CNPq. Tem interesse em História e Teoria da Arte. Link ORCID: https://orcid.org/0000-0001-5823-2638

Link lattes: http://lattes.cnpq.br/9004537654401468 E-mail: adrielzortea@outlook.com

2 Professora de História da Arte da História da Universidade Federal de Santa Catarina (UFSC). Pós-doutorado pelo Centre d'Histoire et de Théorie des Arts (CEHTA) da École des Hautes Études en Sciences Sociales (EHESS) de Paris.

Link ORCID: https://orcid.org/0000-0002-9681-0977

Link lattes: http://lattes.cnpq.br/6762399715666997

E-mail: camposdanielaqueiroz@gmail.com
} 


\section{As ninfas entre a dureza e a fluidez}

O presente artigo tem como principal objetivo analisar três obras da série Saunas e Banhos, da artista plástica brasileira Adriana Varejão (1964-). As análises partem de questões teóricas levantadas pelo historiador da arte alemão Aby Warburg (1866-1929) e por um de seus mais destacados exegetas, o filósofo e historiador da arte francês Georges Didi-Huberman (1953-). Ambos fizeram da ninfa um destacado objeto de estudo.

Foram selecionadas três obras - The Ghest (2004), A malvada (2009) e O Voyeur (2006) - e a elas foram montadas, justapostas de maneira não resumida ou esquematizada, duas destacadas imagens de corpo feminino na história da arte: a Banhista de Valpinçon (1808), do pintor francês Dominique Ingres (1780-1867); e, O Nascimento de Vênus (1483) de Sandro Botticelli (1445-1510), esta última já analisada como ninfa por Warburg em sua tese de doutorado, defendida no ano de 1893 (WARBURG, 2015), e em seu Bilderatlas Mnemosyne (WARBURG, 2010), como também por Didi-Huberman (DIDI-HUBERMAN, 2005).

Em suas análises empreendidas sobre o corpo pintado na Florença do Quattrocento por Botticelli, Aby Warburg nomeou de ninfa a imagem feminina em movimento acentuado. As imagens da ninfa, em Warburg, são comumente associadas a movimentos externos, como nos drapeados de cabelos e vestimentas. Sobre ela, Warburg escreveu também fictícia correspondência com o linguista André Jolles (1874-1946), acerca de afresco pintado na Igreja Santa Maria Novella de Florença por Domenico Ghirlandaio (1449-1494). No texto, apontou-a como a criada no Nascimento de São João Batista (1490), no coro da igreja florentina (WARBURG, 2018, p. 68).

O intento é analisar as cinco obras a partir de notáveis semelhanças imagéticas, percebíveis em elementos advindos da obra de Aby Warburg e Georges Didi-Huberman: sendo eles, nachleben e pathosformel. A partir de sua tese, Warburg viria a elaborar a nachleben, a pós-vida da imagem, que Didi-Huberman (DIDI-HUBERMAN, 2013; 2017b), opta por traduzir por "sobrevivência" (survivance); a imagem do tempo sobrevivente. O pathosformel diz respeito a uma carga energética, transmitida e transformada, na longa duração, através da gestualidade corpórea humana. A pathosformel é a plasticidade da nachleben.

Em suma, a nachleben dos corpos femininos em movimento foi resumida por Warburg numa personagem transversal e mítica, a heroína da pathosformel: a ninfa (DIDI-HUBERMAN, 2013, p. 219). Para o historiador da arte argentino José Emilio Burucúa, a ninfa é um topos na obra de Aby Warburg (BURUCUA, 2003, p. 15). As imagens de Adriana Varejão selecionadas foram abordadas como ninfas a partir desses dois elementos. As obras selecionadas foram produzidas em óleo sobre tela ou grafite sobre papel. Possuem um elemento, como destaca Lilia Schwarcz em Pérola Imperfeita (2014), caro à artista: o azulejo. É importante destacar que Adriana Varejão não opera com o azulejo propriamente dito, mas com sua imagem projetada sobre a tela. $O$ azulejo é exposto, apresentado e manipulado através da tinta da artista.

As obras da série Saunas e Banhos são marcadas por ambientes monocromáticos cobertos por azulejos de dureza e frieza material. Contudo, como reduto para a 
figura humana, apesar do suposto interior vazio do ambiente produzido para a impermeabilidade que é a da sauna/banho, encontra-se sobreposto ao azulejo a imagem do corpo. A ninfa foi indicada no contraponto entre a alvenaria e o azulejo - a dureza da pedra - e a liquidez do sangue e da água - a fluidez do orgânico - bem como, na tenaz sobrevivência de formas em movimento, como os cabelos insuflados de ar ou nas manchas esparsas de sangue sobre a alvura. A ninfa, imagem ligada à drapearia em movimento na história da arte, foi aqui problematizada também a partir da dureza de um azulejo pintado por Adriana Varejão.

\section{Adriana Varejão e as formas em movimento}

As imagens da artista plástica carioca Adriana Varejão condensam referências e regurgitações de diversas obras de um mundo-imagem sempre passível de ser ampliado. A artista, nascida na cidade do Rio de Janeiro em 1964, filha de um piloto de aeronáutica e de uma nutricionista (MORAES, 2013, p. 19), possui extensa e significativa obra no contexto artístico contemporâneo brasileiro e também no circuito internacional de arte. Entre diversas exposições, individuais e coletivas, alocadas em diversos museus e espaços culturais ao redor do mundo, destaca-se o pavilhão exclusivo dedicado à sua obra no Museu do Inhotim, em Brumadinho (MG). Ademais, obras de sua significativa atividade artística fazem parte de acervo de museus como o Guggenheim Museum e o The Metropolitan Museum of Arte, em Nova York (EUA), o Tate Modern, em Londres (Reino Unido), e a Fondation Cartier pour l'arte contemporain, em Paris (França).

De suas exposições individuais, uma das últimas, realizada no ano de 2019 e apresentada no Museu de Arte Moderna da Bahia (MAM-BA), sublinha em seu título - Por uma retórica canibal - a operação levada a cabo por Varejão há cerca de três décadas. Trata-se, enfim, de modificar o já existente, mesclar o novo e o antigo através de uma (re)visualização do mundo que se propõe arborescente e não-resolutiva. Não se trata, simplesmente, de introduzir elementos heterogêneos, mas de fazê-los debater através de cristalizações e rasgos duradouros de sentido sempre derivados e não-fechados.

A artista ressalta, em textos e entrevistas, o impacto significativo que teve o Barroco mineiro sobre a sua obra. Se antes de visitar Ouro Preto Varejão já costumava saturar a tela com muita tinta (MORAES, 2013, p. 19), mais tarde, a cor em relevo tornou-se predominante em suas imagens. Se o Barroco pode ser apontado como importante na obra de Varejão, entre diversos temas, suportes e materiais, o azulejo - pintado, apresentado, produzido pela artista - possui local de destaque em suas imagens. Os azulejos estão significativamente presentes em sua obra em duas grandes séries: Saunas e Banhos e Charques, ambas produzidas a partir da virada do século $X X-X X I$.

Destaca-se, aqui, a primeira série. Segundo Lilia Schwarcz a artista já havia trabalhado com imagens de azulejos em outras obras, como Azulejões (2000), mas Saunas e Banhos abriram novas perspectivas ao comportarem-se como série e conjunto (SCHWARCZ, 2014, p. 234). Defende-se que as imagens em questão, fechadas em 
sua interioridade e sua tentativa rasurada de vazio e não-existência humana, evocam o corpo humano no azulejo, seja em sua forma, ou, no sangue e cabelo que pairam sobre a alvura da alvenaria. Nesse lugar de antropomorfismo dilacerado, não há humanidade tal qual se concebe na arte: não há rostos, não há curvas, não há membros apresentados. Existe a imagem humana "indicada por índices, por vestígios e por dessemelhanças - no próprio lugar de sua ausência" (DIDI-HUBERMAN, 2018b, p. 144).

As associações entre as obras de Adriana Varejão e as ninfas foram aqui propostas pelas similitudes de formas notadas em algumas obras selecionadas. Por exemplo, como nos nomeados por Aby Warburg de acessório em movimento (como o cabelo), encontradas em $A$ malvada e em $O$ nascimento de Vênus, de Sandro Botticelli. Bem como, na forma em movimento que se dá a ver pelo sangue em The Guest, essencialmente fluido, acumulando-se sobre o azulejo; ou, na própria dureza e frieza da alvenaria e do ambiente ladrilhado, que muito possui em comum com a carne cinzelada da Vênus, pintada ao modelo dos baixos-relevos da Antiguidade. As características listadas - a forma fluida e em movimento do sangue, a forma do cabelo serpentino esquecido no banho, bem como, a dureza e frieza do azulejo, comparável àquela da carne venusiana podem sugerir não apenas características iconográficas e poéticas da imagem, mas também patéticas (DIDI-HUBERMAN, 2002, p. 132).

Imagens de corpos em movimento ou de resquícios de corpos, problematizados como ninfas, serão associadas neste trabalho a partir de suas relações. Afinal, as imagens não falam de maneira isolada. É preciso colocá-las em relação (DIDI-HUBERMAN, 2011). As semelhanças pertencem às relações visuais abertas pelo olhar do espectador; são ligadas ao inverificável (DIDI-HUBERMAN, 2002, p. 129).

Pois, para ler atentamente a própria artista, "a arte se alimenta da arte, e não da natureza" (VAREJÃO, 2005, p. 01), maneira sofisticada de enunciar o modelo de tempo complexo e impuro convocado pela historiografia artística contemporânea, notadamente, a escrita por Georges Didi-Huberman. A imagem, ao se apresentar de uma só vez diante de seu espectador, libera uma extraordinária memória latente (DIDI-HUBERMAN, 2017a, p. 27). Didi-Huberman abre a história da arte às dobras de tempo e aos nós intrincados de anacronismos (DIDI-HUBERMAN, 2017b).

As associações dizem respeito à montagem de imagens. Particularmente, a montagem foi operada por Aby Warburg no Bilderatlas Mnemosyne (2010), o Atlas de imagens que ocuparia Warburg até o fim de sua vida em 1929. Esse é um experimento imagético composto por 79 pranchas com dimensões de 1,5m por $2 \mathrm{~m}$, cobertas de tecido preto, compostas por imagens de distintos tempos históricos alocadas juntas. Georges Didi-Huberman aponta o Atlas como forma visual do saber (DIDI-HUBERMANM 2018a, p. 18). A montagem do Atlas produziu um pensamento por imagens para perceber singularidades e afastamentos nas experiências humanas. Difere-se, portanto, de um catálogo, ou, de um dicionário: não é uma lista integral, mas um pensamento por associações desdobradas, não-esquematizadas.

Em Mnemosyne, a ninfa ensaia "o pequeno teatro da memória da Nachleben der Antike" (DIDI-HUBERMAN, 2002, p. 133). As ninfas movimentam-se nas pranchas, sem se fixarem a determinado local ou tempo. Georges Didi-Huberman, como Aby Warburg, encontra a ninfa em e no movimento. Mas o movimento sobre o qual es- 
creve Didi-Huberman em Ninfa Moderna - essai sur le drapé tombé (2002) é também o do declínio. Elas haveriam declinado com a modernidade; encontram-se, agora, caídas, estendidas sutilmente em posição horizontal, às vezes semideitadas; não mais eretas e esguias como outrora.

Todavia, como cristalização sensível de uma dialética entremeada ao tempo - como esse historiador da arte que é também filósofo da arte defende em tantos de seus trabalhos - o movimento do declínio marca também, apesar de tudo, o da sobrevivência. Incapazes, como toda forma humana, de puramente desaparecer, as ninfas são capazes de outras vidas, outros corpos, outras imagens. Enfim, a possibilidade desse texto é a de problematizar a ninfa nos movimentos e formas fluidas nos azulejos de Varejão. Analisar, principalmente, as imagens do sangue quente, orgânico, e a forma drapeada do cabelo, contrapostas à arquitetura inorgânica do azulejo, duro e impenetrável.

\section{As ninfas nas obras de Adriana Varejão}

Para Giorgio Agamben, a ninfa é objeto de paixão amorosa por excelência (AGAMBEN, 2012, p. 40). Pode-se perceber desejo dissimulado na série Saunas de Adriana Varejão. Segundo o crítico de arte brasileiro Paulo Herkenhoff, "os títulos das Saunas indicam intenso labor psicológico sado-freudiano" (HERKENHOFF, 2005, p. 02). Nas três imagens de Saunas selecionadas e analisadas neste trabalho, o teor de desejo atrelado aos azulejos é evidente.

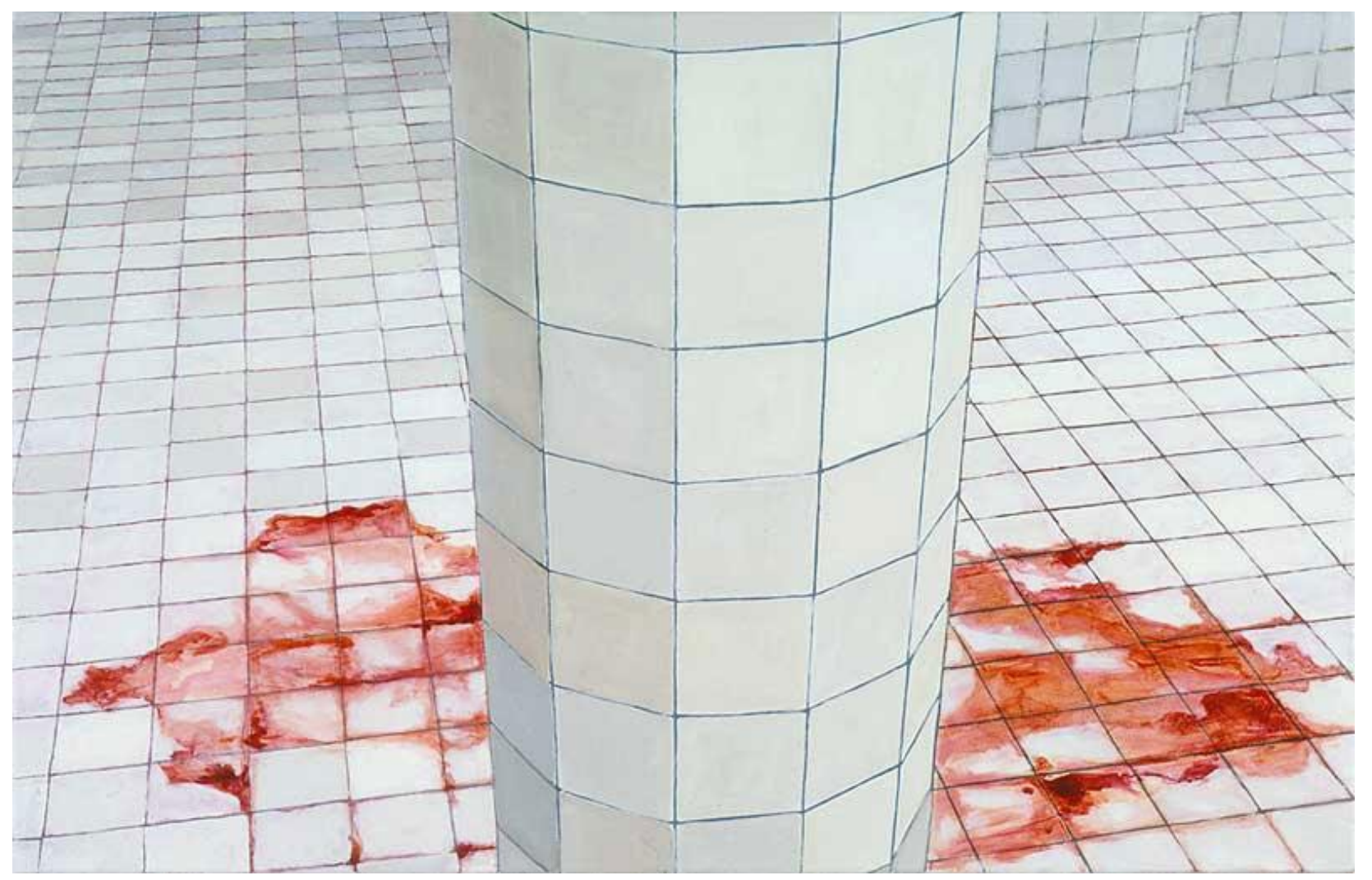

Figura 1. Adriana Varejão. The Guest. Óleo sobre tela, 45 x 70 cm, 2004. Fonte: http://www.adrianavarejao.net/br/home 
A imagem acima (figura 1), denominada por Adriana Varejão como The Guest, foi produzida no ano de 2004 em óleo sobre tela. Possui dimensões de $45 \times 70 \mathrm{~cm}$. Como é comum na série Saunas e Banhos, a obra em questão apresenta um ambiente quase monocromático, revestido de azulejo. $O$ branco que captura o olhar num primeiro momento, contudo, parece ganhar um matiz de cor mais ampla e diversificada quando os olhos pousam sobre a imagem um pouco mais languidamente. As tonalidades de um azul fraco, de um tom rosa singelo e de um violeta manchado ganham espaço. Todavia, é o vermelho que disputa com o branco o espaço da imagem. O vermelho de uma mancha esparsa e inconstante sobre o chão, o rubor evidente de sangue, amarelado ou alaranjado, ocre, em alguns lugares, como no canto inferior direito da imagem.

A coluna, azulejada na mesma tonalidade, é propositalmente inserida em meio à mancha de sangue, encobrindo-a, parcialmente, levando-se a indagar o que poderia haver por detrás, em meio ao sangue entranhado no branco. O espectador está fadado a reconhecer que não descobrirá. A coluna é arredondada, disputando o espaço quadrangular com sua sinuosidade.

Além disso, como a própria pigmentação da obra, a aparente geometria da imagem também parece sofrer alterações ao passo que os olhos se acostumam a ambiente tão hermético. As paredes, linhas verticais, inseridas no canto superior direito, insinuam cortes no azulejo que não os da linha métrica. Há azulejos, no canto superior esquerdo, que possuem tamanho variado, uns maiores que os outros.

À medida que se distancia o olhar do sangue e aproxima-se das áreas mais distantes, o azulejo adquire uma tonalidade mais azulada, anil, até mesmo vibrante, que a apresentada sob o sangue. É fortuito notar que o azulejo mais branco e, por isso, mais associado à higiene e à limpeza, está ele mesmo, em primeiro plano, ao lado da excreção, do fluído corporal, do sangue, como se a sujeira e a limpeza estivessem associadas irremediavelmente uma à outra. A cor e o azulejo, aparentemente, estáticos e herméticos, possuem matiz variada quando analisados detalhadamente.

Não se encontra a presença de um corpo tal qual se acostumou a concebê-lo na história da arte. Mas, como imagem, a ausência humana está presente como um rastro ou uma sobra, pois em The Guest o sangue marca a imagem do corpo. A presença do líquido vital do ser humano é a possibilidade de sobrevivência do corpo através de sua ausência. O declínio do corpo, sua não-presença corpórea, apresenta a possibilidade de sobrevir no tempo e no espaço através do resquício. Pode-se enunciar que Varejão opera aqui com o fragmento: a migalha do corpo, mas também o do material cinzelado e rompido em pequenos pedaços encaixados que é o azulejo.

Ademais, o sangue enuncia debate sofisticado: diz respeito à morte, ainda mais em espaço tão limpo e esterilizado que é o do ambiente azulejado. Mas o sangue não é apenas a ausência, mas também a vida, como a pulsação de um corpo em plena atividade fisiológica, o sangue do trabalho de parto, da placenta e da menstruação. $O$ sangue de um corpo feminino.

A própria artista Adriana Varejão escreveu que o "sangue brota pelas fendas. Insinua-se uma narrativa" (VAREJÃO, 2005, p. 04). Uma narrativa que se desdobra enquanto se observa a imagem. É impossível permanecer "neutro", tal como sugere 
o ambiente tão fechado em seu silêncio, ao mesmo tempo não-externo e exposto. Trata-se de insinuar ver na imagem uma série de movimentos instaurados e reivindicados pela pintura enquanto ato de figura figurante, capaz de metamorfose. Transformação que abre o banho - ou, talvez, dado o extenso uso do azulejo em outros ambientes (restaurantes, fábricas, abatedouros, açougues) - à problemática da sobrevivência do corpo humano.

Ocorre a ver no sangue, apesar da ausência de estrutura morfológica, o corpo humano. Isto porque The Guest traz consigo a carga imagética do corpo semelhante a qualquer outro, ao sangue do seu próprio espectador liquefeito sobre a alvura do azulejo quadrangulado. A presente tela "é o retorno dos corpos. Sua carga simbólica insiste em intrometer-se no olhar" (HERKENHOFF, 2005).

Analisamos e problematizamos a figura da ninfa na obra The Guest principalmente através de dois aspectos: a contraposição entre o sangue quente e vermelho que cobre o azulejo branco e frio; e, na própria forma ondulada da mancha sanguínea espalhada sobre o chão ascético, ou seja, o movimento do sangue.

A primeira indicação é plausível pois o azulejo não possui organicidade, tal qual a Vênus de Botticelli, cujo corpo duro muito se assemelha a esse azulejo frio; a intensidade da obra, como descrita por Didi-Huberman (2005, p. 40), encontra-se nos arredores do corpo de Vênus, e não em sua estrutura corpórea. Como no corpo de Vênus, pintado à maneira dos baixos-relevos da Antiguidade - analisado a seguir - o azulejo é marcado por uma geometria fria e racional, o elemento orgânico está nos arredores, seja nas ondas do mar e nos ventos de Botticelli, ou, no sangue estirado sobre o chão na imagem de Varejão.

A segunda associação com ninfas diz respeito à forma do sangue: é ela que denota intensidade e movimento - páthos - à obra em questão. O sangue apresentado não está estático ou restrito a apenas um local, pois ele se acumula de forma variável sobre a superfície, produzindo camadas mais ou menos consistentes de matéria; pode-se pensar tanto na fluidez essencial desse líquido estendido sobre a superfície, como no movimento de ir e vir em que escorre para acumular-se em determinada área. Tal como $O$ nascimento de Vênus de Sandro Botticelli, o vestígio sanguíneo em The Guest apresenta a fluidez que acompanha a ninfa.

A obra marca a sobrevivência de formas em movimento, a nachleben de Aby Warburg, através do líquido fluido e quente que se movimenta - seca, espalha-se, acumula-se, prolifera-se - ao contrário da lisura do material que contamina. Em The Guest não se encontra corpo curvilíneo ou alongado, pintado, esculpido ou desenhado. Está-se diante de material de alvenaria tornado corpo humano impenetrável, em sua frieza de material inorgânico. Tal como em Botticelli, está-se diante de material de alvenaria impenetrável, em sua frieza de material orgânico. Monocromático em sua palidez branca.

O corpo, evidentemente em declínio pois dele não se visualiza mais do que uma mancha vermelha sobre o azulejo, marca a permanência da imagética humana. Pode-se dizer sobre The Ghest o que Didi-Huberman escreveu sobre o movimento da Ninfa na Modernidade. “(...) a forma humana está ausente, de fato. Mas permanece em suspenso - ou melhor, em retirada, em resto -, como última forma possível para o desejo humano" (DIDI-HUBERMAN, 2002, p. 24). 
A carne, o tom branco marmóreo, a imagem impregnada de elemento humano da imagem analisada acima, pode ser associada a outra imagem. Outra obra problematizada como ninfa, produzida em contexto muito diferente que o da arte contemporânea brasileira de Adriana Varejão. Trata-se de pintura de Jean-Auguste Dominique Ingres, produzida no ano de 1808. As questões imagéticas de Ingres e Varejão são distintas. Contudo, suas imagens podem ser aproximadas através do saber-montagem, como reivindicado nos pressupostos de montagem de imagens de Aby Warburg e Georges Didi-Huberman. Outra imagem capaz de apresentar, diante dos olhos de seu espectador, a problemática da ninfa.

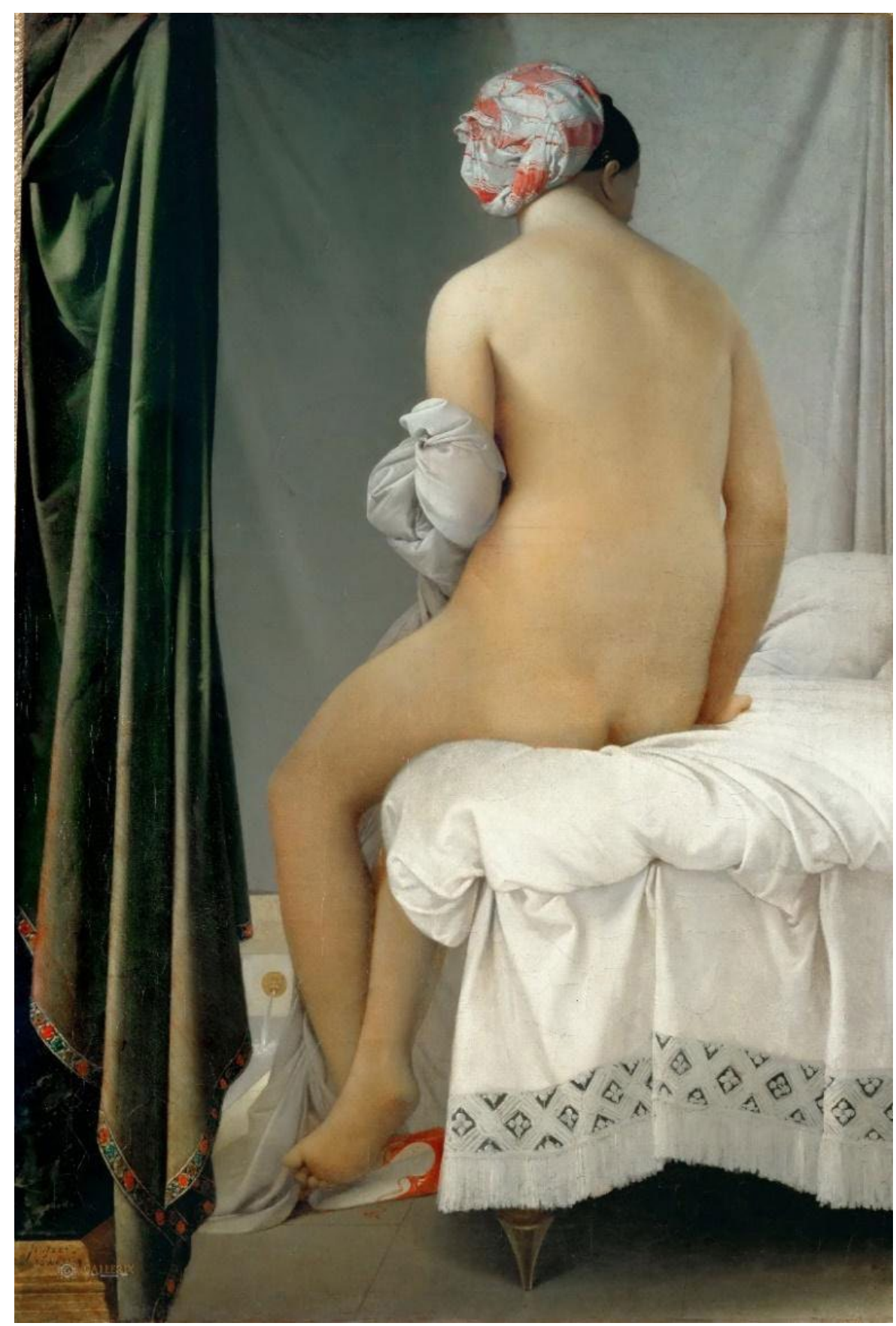

Figura 2. Jean-Auguste Dominique Ingres. Banhista de Valpinçon, 1808. Óleo sobre tela, 146 x $97 \mathrm{~cm}$. Museu do Louvre. Fonte: https://pt.wikipedia.org/wiki/A_Banhista_de_Valpin\%C3\%A7on\#/media/Ficheiro:Jean-Auguste-Dominique_Ingres_-_La_Baigneuse_Valpin\%C3\%A7on.jpg 
A Banhista de Valpinçon (figura 2), óleo sobre tela de 1808, foi pintada pelo artista francês Jean-Auguste Dominique Ingres na Paris do século XIX. O pelo pintor. A obra foi produzida no contexto de belas e eróticas imagens de banhos, notadamente, os orientais. Está-se diante de um corpo feminino visto de costas. A pele da personagem é clara, capaz de adquirir uma tonalidade amarela em algumas regiões corpóreas, como nas pernas e pés; ela se encontra nua, enrola sobre seu antebraço um lençol branco, que cai diante de suas pernas até atingir o chão. Além do tecido branco, a única peça a cobrir a personagem é um toucado multicor, enrolado em seus cabelos, em branco e alaranjado.

É interessante notar que a personagem se encontra de costas para o seu espectador, levemente "torcida" em posição lateral, virada para a sua própria esquerda. Seu rosto, ao contrário, está voltado para a direita. Insinua-se, levemente, a parte superior de suas nádegas, mas seus seios, sua vulva e seu próprio rosto encontram-se ocultos da visão do espectador. O seu pé esquerdo também está escondido; desaparece atrás do pé direito, do qual se pode perceber os dedos e a sola, pintada em tom ocre tal como outras partes do corpo. De seu rosto observa-se apenas sua orelha e os traçados de seu nariz e cílios.

As cores claras, os tons esbranquiçados, dominam o fundo da imagem. A cor escura está presente nos cabelos da personagem, bem como sob a cama, e na cortina verde inserida na lateral esquerda da imagem. Sobre a Banhista, o historiador da arte italiano Giulio Carlo Argan escreveu que a tela possui redução ao mínimo do aparato cênico: não se pode distinguir se a mulher sai ou entra no banho; sobre o espaço, pode-se dizer que é uma sala de banho pela água que escorre de uma torneira dourada, jorrando água, ao lado esquerda das pernas da personagem (ARGAN, 1992, p. 52).

O drapejo é outro elemento recorrente na imagem em questão. Há tecido tanto na mão da personagem, como sobre a cama. Pode-se ressaltar a textura das roupas de cama, tão próximas em suas dobras que parecem passíveis de serem tocadas. Como se sabe, o drapejo pode ser, nos estudos de história da arte, tributário da famosa fórmula de páthos de Aby Warburg, explicitada, pela primeira vez, um pequeno texto de 1905 acerca de Orfeu, do pintor alemão Dürer. Ali, o historiador da arte alemão indicava "com que viva intensidade a mesma fórmula de páthos, arqueologicamente fiel e que remonta à representação de Orfeu ou de Penteu, enraizou-se nos círculos de artistas" (WARBURG, 2015, p. 90). A ninfa pode ser aqui indicada a partir da pathosformel da qual é a heroína feminina. Segundo Georges Didi-Huberman, a pathosformel possui vocação para "intensificar o afeto na forma" (DIDI-HUBERMAN, 2013, p. 209).

A imagem pode ser associada para com as ninfas através da pathosformel, dos tecidos em dobras da cama, e os pequenos trechos de pano que se torcem sobre o braço e cabeça da personagem. Eles marcam a intensidade do ambiente, de forte teor erótico, apesar da postura não-frontal da personagem, que não mira os olhos para o seu espectador, ao contrário de outras imagens de nu feminino que a antecederam, como a Vênus de Urbino (1534), pintada pelo pintor Ticiano (1490-1576), no Renascimento.

A imagem possui em comum com a imagem anterior o elemento vermelho exposto sobre a alvura. O tom branco, contudo, é o da drapearia e também o do próprio 
corpo da mulher, ao passo que em Varejão é o azulejo que demarca a cor. O vermelho, não mais sangue na Banhista, ainda salta o olhar nos tons de seu toucado, e nas pesadas franjas dos tecidos, tombados diante de seus pés. Aqui não se encontra azulejo, como na imagem anterior, mas encontra-se o corpo feminino em sua tenaz sobrevivência (nachleben) e em seu elemento de intensidade erótica. A sauna, tal como o banho, é o lugar da transgressão sexual (SCHWARCZ, 2014, p. 241). Em ambas as obras se encontram resquícios humanos. Indicam-se Ninfas.

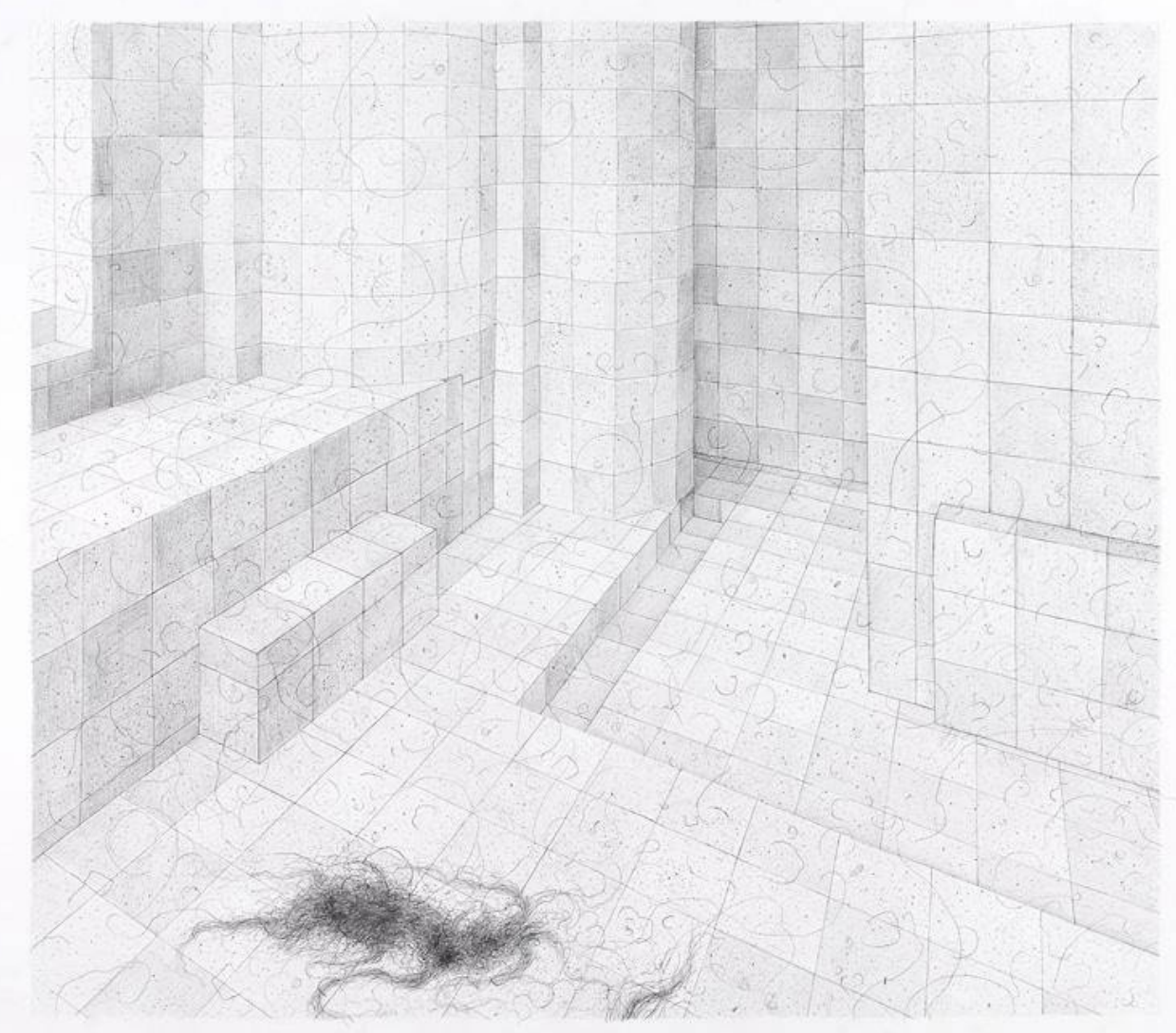

Figura 3. Adriana Varejão. A malvada, grafite sobre papel, 70 x $100 \mathrm{~cm}$, 2009. Fonte: http://www.adrianavarejao.net/br/home

Drapearia, azulejo, corpo humano são encontradas em outra obra de Adriana Varejão. A obra $A$ malvada (figura 3), como em The Guest, e diferentemente de $A$ banhista de Valpinçon, há ausência de água. A profundidade do azulejo, insinuando um reduto de área molhada, encontra-se seco. Nota-se que um jogo de luz parte do canto superior esquerdo, dirigindo-se ao canto superior direito, como se uma janela estivesse aberta. As paredes mais ao fundo, como nas outras imagens, são as mais escuras. O branco, torna-se ocre e acinzelado nos azulejos. As formas retangulares e quadriculares são visíveis, como blocos sobre o chão e ao lado das paredes, um, como uma espécie de degrau, à esquerda, e outro, pouco espesso, mais comprido que o outro, ao lado da parede direita. Contudo, o canto entre paredes possui formas arredondas e avolumadas, como colunas. O segundo plano da imagem é dominado por um quase "campo minado" de blocos friamente herméticos, tijolos e alvenaria cobertos por azulejos. 
Pequenos rabiscos, espalhados pelos azulejos, retomam a visualidade de cabelos, espalhados por todo o azulejo, esparsamente em quase todo canto, mas nitidamente concentrados em uma região, no primeiro plano da imagem. Presença nova, portanto, é o chumaço de cabelo preto, que contrasta com o branco do azulejo. A aparência dos cabelos é estranha e familiar ao mesmo tempo. Demarca a imagem do corpo humano. As madeixas maltrapilhas insinuam a passagem do corpo, como se as banhistas do neoclassicismo deixassem seu banho para trás e a água evaporasse. Como em The Ghest, o ambiente higienizado, limpo - de lógica racionalista - é contraposto ao resquício do corpo, a sobra avulsa do cabelo esquecido ao banho.

O ambiente do banho, o desprendimento do cabelo humano e a ausência da carne introduzem a questão da pathosformel. Como já salientado, o cabelo e as vestes das ninfas warburguianas pintadas em têmpera por Botticelli, possuem seu elemento de intensidade no externo, no tecido ao vento, nas madeixas ao chão. Portanto, pode-se indicar a ninfa em $A$ malvada através do "acessório em movimento", os cabelos e as drapearia insufladas de ar, que foi reivindicado como exímia vitalidade a partir das obras da Antiguidade, como percebeu Aby Warburg. Esse erudito escreveu que a mobilidade exterior poderia acrescentar-se aonde quer que fosse necessário trazer à tona a aparência de uma vida intensificada (WARBURG, 2015, p. 84). O elemento de vitalidade na obra em questão está presente na forma do cabelo esquecido ao chão.

A ninfa pode ser problematizada a partir das madeixas de cabelo esquecidas sobre o azulejo, a partir de dois argumentos: a forma serpentina dos fios e, a horizontalidade desses estendidos ao chão. Primeiramente, portanto, é através da forma do cabelo que se denota a ninfa na obra, pois os cabelos, se desprendidos do corpo, solitários, ao colocarem em questão a presença do corpo, confirmam o vestígio e condicionam o elemento de intensidade da obra, tal qual nas ninfas de Aby Warburg. Se o cabelo não se encontra em movimento, a sua forma permanece na obra, apesar de não ser nem belo nem gracioso como o a criatura botticelliana. Em seguida, pode-se sublinhar que a horizontalidade do cabelo, desprendido, avulso, esquecido, se assemelha ao próprio movimento de queda da ninfa descrito por Didi-Huberman: as formas em movimento da ninfa ganham o chão. Tal como reivindicado por Didi-Huberman, o cabelo aqui mais se assemelha à sobra e ao trapo (DIDI-HUBERMAN, 2002, p. 63). Aqui, novamente se encontra a dureza do azulejo, bem como sua cor fria e monocromática. Contudo, a brancura não se encontra contraposta ao vermelho orgânico do sangue, pois domina quase por completo o ambiente. A textura que difere da alvenaria é a da forma do cabelo.

A malvada, de Adriana Varejão, não se subtrai de seu verdadeiro poder de tocar o espectador que a observa ao insinuar a sobra do corpo. Se o segundo plano da obra apresenta demarcadores de espaços - quinas, colunas, degraus, declives de altura e comprimento - não se pode extrair do olhar que parte e se remete ao espectador composto pelo chumaço de cabelo humano em primeiro plano. Como o sangue em The Guest e o corpo de rosto oculto de A banhista de Valpinçon, a imagem marca a ausência pela presença do derivado do corpo humano; sua vocação a demarcar o corpo através da dureza do azulejo, como pelo cinzel esculpiam-se baixos relevos na Antiguidade. O cabelo, a drapearia, o azulejo duro e frio, remetem a outra imagem, de outro tempo. 


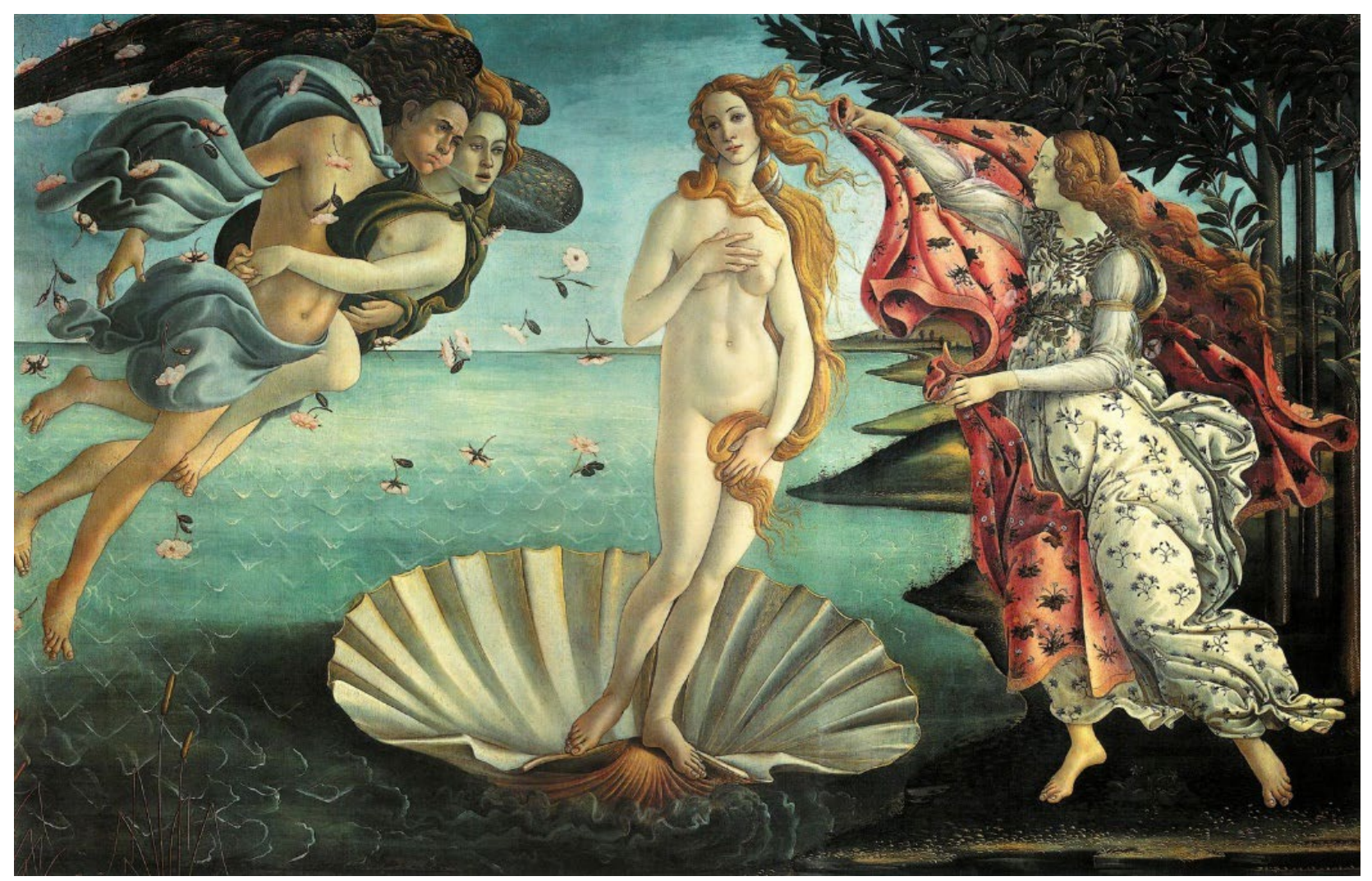

Figura 4. Sandro Botticelli, O nascimento de Vênus, $172,5 \mathrm{~cm}$ x 278,5 cm, c. 1485. Galleria degli Uffizi, Florença. Fonte: https://pt.wikipedia. org/wiki/Ficheiro:El_nacimiento_de_Venus,_por_Sandro_Botticelli.jpg

A pintura $O$ nascimento de Vênus (figura 4), de Sandro Botticelli, foi minuciosamente analisada por Aby Warburg na primeira parte de sua tese de doutorado, datada de 1893, denominada de $O$ nascimento de Vênus e A primavera de Sandro Botticelli - uma investigação sobre as concepções de Antiguidade no início do Renascimento italiano (WARBURG, 2015, p. 27). Neste trabalho, Warburg havia se detido à ninfa ao estudar como os artistas e teóricos renascentistas viam, nas obras legadas pela Antiguidade, um modelo que necessitava de movimento acentuado e como, observando esses modelos, conseguiam o traçado de partes acessórias - os trajes, os cabelos cujo movimento é aparente (WARBURG, 2015, p. 27).

A tese de Warburg é a de que se recorria às artes plásticas da Antiguidade quando era preciso buscar modelos para o movimento, com Angelo Poliziano (1454-1494), como Botticelli, atento às descrições referentes aos movimentos. Essa "brisa imaginária" capaz de insuflar as mechas de cabelo e as peças de roupa, era opinião consolidada nos círculos artísticos do Renascimento quando se tratava de pintar figuras em movimento (WARBURG, 2015, p. 33). A pathosformel, termo ainda não cunhado por Warburg - seria, como já salientado, apenas em 1905, em seus estudos sobre Dürer - é nitidamente percebível em suas formulações acerca da pintura feita por Botticelli.

A questão é que, ao se deparar com o acentuado movimento que circunda as figuras femininas, Warburg notara relação entre o pintor Botticelli, os poemas de Poliziano e os próprios hinos homéricos. Para Philippe-Alain Michaud, se o artista do Renascimento, como formula Aby Warburg, "se volta para a Antiguidade a ponto de 
se identificar com ela, não é para encontrar ali um repertório de imagens, mas para injetar nela as fórmulas expressivas que representarão a vida" (MICHAUD, 2013, p. 77).

Para Warburg, pintores e teóricos renascentistas voltavam-se para a Antiguidade para encontrar fórmulas expressivas que os auxiliassem em apresentar a vida em movimento. Encontravam na Antiguidade, em suas imagens e em seus textos, maneiras que poderiam "dar corpo à vida em movimento aparente" (WARBURG, 2015, p. 49), como é o caso da ninfa. A utilização da imagem feminina em movimento era uma fórmula que não derivava da observação da natureza por parte do artista (SZIR, 2019, p. 24).

Aponta-se a tela aqui a partir de dois elementos: o movimento acentuado do cabelo e das vestimentas - tratados por Aby Warburg como pathosformel - cujo retorno encontra-se presente na tela de Varejão pintada acima; e, a dureza da carne, marmórea, presente no escultórico corpo de Vênus. Ao contrário da imagem anterior, A malvada, os "acessórios" da ninfa em Botticelli encontram-se em movimento. O vento é soprado pela boca de Zéfiro, no canto esquerdo da imagem, projetando ar sobre os cabelos louros de Vênus e sobre a deusa Primavera, no canto superior, que possui as dobras das roupas levantadas pelo ar. Como A malvada, contudo, possuem o páthos como elemento de intensidade. É fortuito analisar que a água é de um tom verde, mais escura na rasura, perto de onde a concha de Vênus chega em sem percurso, do que nas regiões mais fundas, que adquirem uma tonalidade mais clara, azulada.

Georges Didi-Huberman escreveu que a imagem corpórea da Vênus pintada por Sandro Botticelli - analisada como ninfa - é dura: cinzelada, escultórica, mineral, à maneira dos baixos-relevos da Antiguidade. "O corpo de Vênus parece ser de um mármore muito liso e muito frio" (DIDI-HUBERMAN, 2005, p. 19). Ao contrário da Banhista de Valpinçon, cuja carne, apesar da postura lateral da personagem, é quase passível de ser tocada, a textura da Vênus é, como bem salientou Didi-Huberman, fria e mineral. Diante da imagem do corpo de Vênus é como se o expectador mirasse a dureza de um mármore. Duro e frio como um azulejo, como os azulejos pintados pela tinta de Adriana Varejão. 


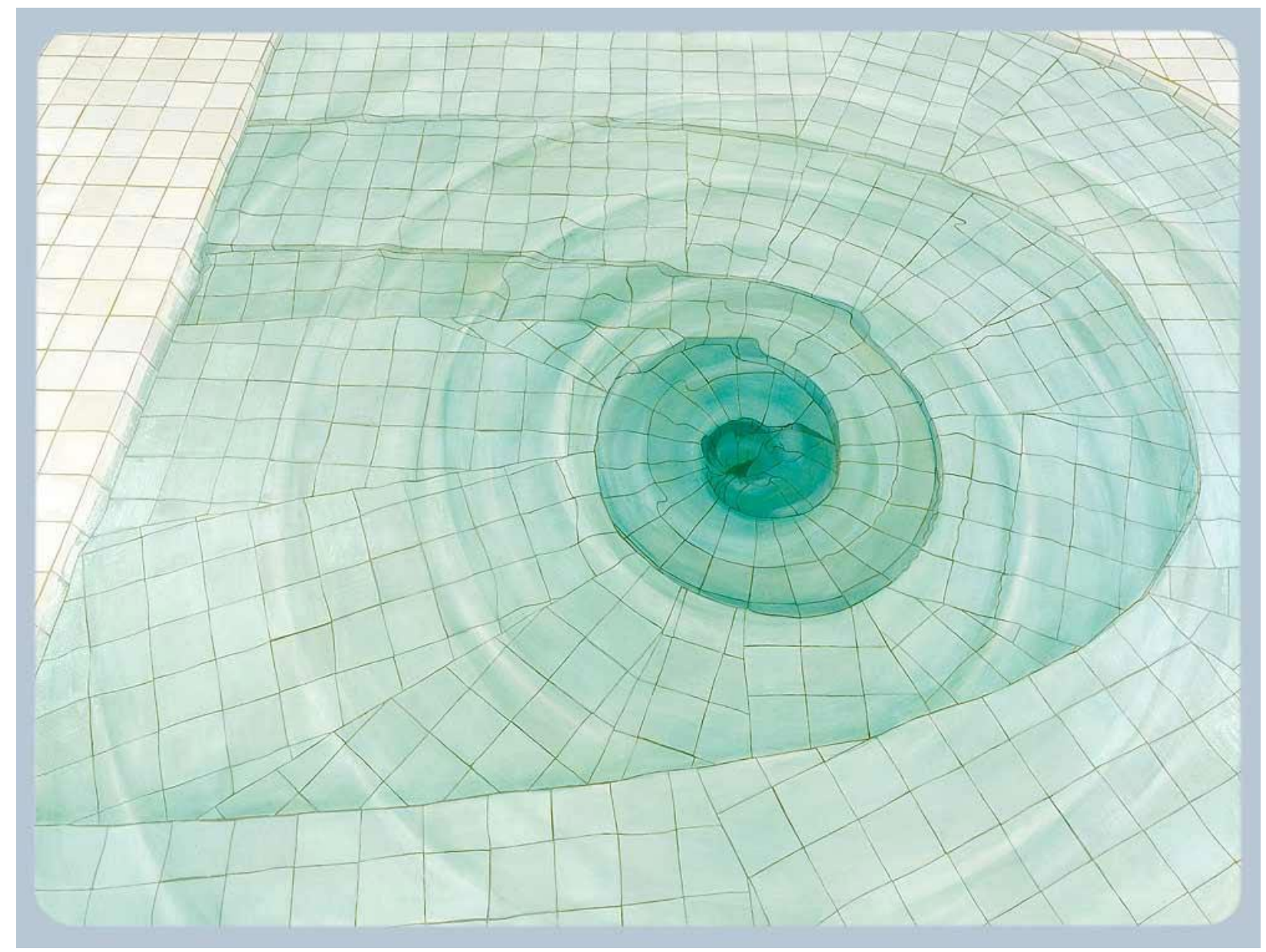

Figura 5. Adriana Varejão, The Voyeur, óleo sobre tela, 160 x 215 cm, 2006. Fonte: http://www.adrianavarejao.net/br/imagens/categoria/10/ obras

Um corpo na água, pousado e suspenso. Apresenta-se aqui, como última imagem (figura 5) um outro corpo na água, mas submerso, liquefeito; entremeado pela água não mais salgada do mar Egeu. Pertence à água doce de uma piscina. A última imagem não possui destaque no elemento de cor vermelha. Tal como a primeira, porém, evoca o azulejo em tons brancos e azulados. Se as linhas métricas também adquirem curvas ao dilatar do olho atento, o elemento novo inserido pela artista em The Voyeur fica por conta da água e da profundidade. Uma piscina ganha espaço considerável da imagem, montada em azulejos de tons verdes de lápis-lazúli e índigo.

À medida que a profundidade da piscina cresce - visíveis na imagem pela forma espiralada adquirida, bem como pela intensificação da cor do azulejo como artifício para a aquisição de tensão espacial - torna-se mais difícil identificar o tamanho dos azulejos, como se degraus seguissem um atrás do outro até uma região abaixo, talvez, distante da superfície. Ao contrário de Vênus, o tom verde é destacado do fundo, e não na rasura da piscina, como no mar Egeu de Botticelli.

Nota-se que, disposta de maneira retangular e, evocando laterais também retas - como na área circundante à piscina - a região coberta por água aparenta uma forma oval, elemento ainda mais intenso quando o sujeito mira o espaço submerso. Ao atingir o que parece ser o fundo da piscina, perde-se a distinção - a separação - entre um azulejo e outro. É como se a água turvasse o olhar; ao passo que a cor 
se torna mais forte, o espaço torna-se mais sinuoso. A imagem pode ser problematizada como ninfa a partir de três elementos: o primeiro é a forma humana feminina evocada pelo azulejo, pois a torção do líquido em um torvelinho e a maneira como a piscina afunila-se, pode evocar a imagem de uma vulva ou um ânus, através da intensidade do ambiente que denota movimento e ritmo a imagem acima. Ao contrário de $A$ banhista de Valpinçon, cujo corpo está de costas, e de $O$ nascimento de Vênus, cujo cabelo cobre a vulva, as partes íntimas do corpo são dadas a ver aqui. Dureza, enrijecimento, mineral talhado a ponto de aceder pelo cinzel a forma da carne humana, como na imagem anterior (figura 4). A imagem apresenta uma forma humana dissimulada sobre a água e sobre o azulejo, pois pode-se observar parte de um corpo humano na obra. A falta da carne e a presença do azulejo como índice do desejo, apesar de tudo.

Contudo, como segundo argumento, é importante salientar o teor erótico da pintura, pois a ninfa pode ser indicada através dele. Esta foi evocada tanto por Warburg, como por exegetas tais como Agamben e Didi-Huberman, como objeto de desejo. Agamben salientou a ninfa como "figura por excelência do objeto de amor" (AGAMBEN, 2012, p. 55). Particularmente, Didi-Huberman escrevera que a ninfa produz uma verdadeira "erótica dos fluidos" (DIDI-HUBERMAN, 2015b, p. 155). Segundo o último, "o desejo é a própria dialética da imperfeição, do falta-para-ser" (DIDI-HUBERMAN, 2012, p. 83) e nesse limite da figura humana, um ânus, uma vulva, feitos em azulejo, marcam a presente imagem através do exposto, e da falta. O elemento erótico da pintura, maliciosamente disfarçado, diante dos olhos, é reforçado pelo título da obra; como se sabe, o voyeur é a pessoa que sente prazer sexual ao presenciar cenas de sexo. Solapado, de tal feita, mas nem por isso inexistente, é nítido e vibrante o teor erótico associado à imagem corpórea em questão. Na sua frieza, na opacidade de seu ambiente, no vazio instaurado por Saunas e Banhos, talvez seja possível reivindicar lugar para a forma humana

Por fim, a ninfa pode ser evocada aqui a partir do elemento da água. Ela está envolta em água na têmpera de Botticelli, bem como, ao redor de um banho, em $A$ banhista de Valpinçon. Georges Didi-Huberman salienta que o movimento de ir e vir da ninfa no tempo possui algo de semelhante com o vai e vem das ondas do mar (DIDI-HUBERMAN, 2015b, p. 143) e, segundo Giorgio Agamben, a ninfa - ou a ondina - é ligada ao elemento água (AGAMBEN, 2012, p. 55). A cor azul, como já descrita, domina o ambiente. Azul como a água do mar, o líquido da piscina e o azulejo de Adriana Varejão.

\section{Entre azulejos e sobrevivências}

O objetivo deste texto foi procurar ninfas na arte de Adriana Varejão. Ninfas não mais eretas, mas ainda assim em movimento, despertadas pelo próprio poder dos olhos de colocá-las à vida. Levadas à queda que é também sua pós-vida, sua sobrevivência temporal. Segundo as proposições teóricas de Georges Didi-Huberman, a imagem do corpo na arte contemporânea mostra sua relação não apenas com suas questões, mas com a dobra do tempo anacrônica que faz do azulejo imagem humana (DIDI-HUBERMAN, 2018b, p. 144). 
As imagens analisadas demarcam a nachleben da ninfa como tempo sobrevivente que a corporifica. As ninfas foram indicadas em cinco imagens, imagens perpassadas por similitudes e distanciadas por individualidades. Algumas das imagens, como a têmpera de Botticelli, já foram nomeadas e trabalhadas como ninfas por diversos historiadores da arte e teóricos da imagem, principalmente, os dois historiadores da arte cuja importante obra foi aqui destacada. Outras, como as imagens que dão nome e contorno a esse texto, as Saunas de Varejão, ainda não foram problematizadas como ninfas. Aqui, o material de destaque é o azulejo, como pintado nas obras de Varejão. As ninfas podem ser indicadas nos azulejos a partir de sua apresentação de formas de fragmentos humanos, tal como o sangue e o cabelo, pois esses demarcam a nachleben do corpo, principalmente feminino, através de seus movimentos fluidos e intensidades.

As imagens foram analisadas em sua justaposição não-resoluta e desdobradas a partir de dois elementos: pathosformel e nachleben. Estes conceitos foram formulados e aplicados por Aby Warburg de seu primeiro ao seu último texto. Eles dizem respeito a sobrevivência temporal da forma humana, a partir de dobras de tempo, capazes de apontar caminhos espaciais e temporais que não os lineares. "É o funcionamento epidêmico das imagens, para além das fronteiras cronológicas e geográficas, que nos é sugerido" (DIDI-HUBERMAN, 2002, p. 134).

Como nitidamente aplicado por Aby Warburg no saber-montagem que esse desenvolveu em suas obras e pranchas, as imagens apresentam suas semelhanças quando expostas juntas. As imagens demarcam modificações e continuidades na apresentação de corpos humanos na longa história humana. Tal como na obra de Varejão, a ninfa é sempre capaz de outra vida, pois é a heroína impessoal da nachleben warburguiana, incapaz de desaparecer por completo. Warburg "via-a o tempo todo: sempre diversas e sempre em lugares disformes" (WARBURG, 2018, p. 69), e este pequeno escrito intentou apontá-la em imagens repletas de azulejo de uma artista brasileira, tendo o contraste entre o movimento dos líquidos, a fluidez das formas e a dureza do azulejo, como uma possibilidade de acesso às obras, entre outras não-suturadas questões possíveis de serem norteadoras de análises vindouras.

\section{Referências bibliográficas:}

AGAMBEN, Giorgio. Ninfas. São Paulo: Hedra, 2012;

ARGAN, Giulio Carlo. Arte moderna. Do Iluminismo aos movimentos contemporâneos.São Paulo: Companhia das Letras, 1992;

BURUCÚA, José Emilio. Historia, arte, cultura. De Aby Warburg a Carlo Ginzburg. Buenos Aires, Fondo de Cultura Económica, 2003;

BURUCÚA, José Emilio... [et al]. Ninfas, serpientes, constelaciones: la teoría artística de Aby Warburg. Ciudad Autónoma de Buenos Aires: Museo Nacional de Bellas Artes. Ministerio de Educación, Cultura, Ciencia y Tecnología, Secretaría de Gobierno de Cultura., 2019; 
DIDI-HUBERMAN, Georges. Atlas, ou, O gaio saber inquieto. O olho da história, 3. Belo Horizonte: Editora UFMG, 2018 a.

O que vemos, o que nos olha. São Paulo: Editora 34, $2018 \mathrm{~b}$.

Diante da imagem: questão colocada aos fins de uma história da arte. São Paulo: Editora 34, 2017 a.

Diante do tempo. História da arte e anacronismo das imagens. Belo Horizonte: Editora UFMG, 2017b.

A imagem sobrevivente. História da arte e tempo dos fantasmas segundo Aby Warburg. Rio de Janeiro: Contraponto, 2013 a.

A pintura encarnada. São Paulo: Escuta, 2012 a.

A semelhança informe. Ou o gaio saber visual segundo Georges Bataille. Rio de Janeiro: Contraponto, 2015 a.

Ninfa fluida. Essai sur le drapé désir. Paris: Gallimard, 2015b.

La condition des images. In: AUGÉ, M; DIDI-HUBERMAN, G.; ECO, U. L'éxpérience des images. Paris: L'eu editions, 2011.

2005.

Venus rajada - desnudez, sueño, crueldad. Buenos Aires: Editorial Losada, Imágenes pese a todo: memoria visual del Holocausto. Barcelona: Paidós, 2004.

Ninfa moderna. Essai sur le drapé tombé. Paris: Gallimard, 2002.

HERKENHOFF, Paulo. Saunas, 2005. In: Adriana Varejão. Chambre d'échos/Câmara de Ecos. Fondation Cartier pour l'art contemporain/Actes Sud, 2005.

MICHAUD, Philip-Alain. Aby Warburg e a imagem em movimento. Rio de Janeiro: Contraponto, 2013.

MORAES, Marcos. Adriana Varejão. São Paulo: Folha de São Paulo; Instituto Itaú Cultural, 2013.

SCHWARCZ, Lilia Moritz; VAREJÃO, Adriana. Pérola Imperfeita. São Paulo: Companhia das Letras, 2014. 
SZIR, S. A Ninfa. In: BURUCÚA, José Emilio... [et al]. Ninfas, serpientes, constelaciones: la teoría artística de Aby Warburg. Ciudad Autónoma de Buenos Aires: Museo Nacional de Bellas Artes. Ministerio de Educación, Cultura, Ciencia y Tecnología, Secretaría de Gobierno de Cultura., 2019;

VAREJÃO, Adriana. Chambre d'échos / Câmara de Ecos. Entrevista com Hélène Kelmachter, 2004. In: VAREJÃO, Adriana. Chambre d'échos / Câmara de Ecos. Fondation Cartier pour l'art contemporain / Actes Sud, 2005.

WARBURG, Aby. A presença do antigo. Escritos inéditos. Volume 1. Campinas: Editora da Unicamp, 2018.

WARBURG, Aby. Histórias de fantasma para gente grande: escritos, esboços e conferências. São Paulo: Companhia das Letras, 2015.

WARBURG, Aby. A renovação da Antiguidade pagã. Contribuições científico-culturais para a história do Renascimento europeu. Rio de Janeiro: Editora Contraponto, 2013.

WARBURG, Aby. Atlas Mnemosyne. Madrid: Ediciones AKAL, 2010. 